\title{
BAL fluid analysis in the identification of infectious agents in patients with hematological malignancies and pulmonary infiltrates
}

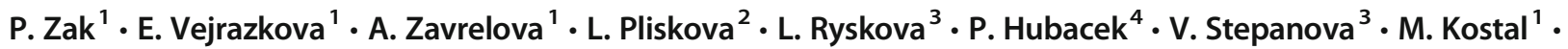 \\ V. Koblizek ${ }^{5} \cdot$ P. Paterova ${ }^{3} \cdot$ Jakub Radocha $^{1}$ (D)
}

Received: 7 September 2018 / Accepted: 25 April 2019 / Published online: 9 May 2019

(C) Institute of Microbiology, Academy of Sciences of the Czech Republic, v.v.i. 2019

\begin{abstract}
The present study aims to evaluate the diagnostic yield of bronchoalveolar lavage (BAL) fluid in patients with hematological malignancies and describe the most common pathogens detected in BAL fluid (BALF.) An analysis of 480 BALF samples was performed in patients with hematological malignancies over a period of 7 years. The results of culture methods, PCR, and immunoenzymatic sandwich microplate assays for Aspergillus galactomannan (GM) in BALF were analyzed. Further, the diagnostic thresholds for Aspergillus GM and Pneumocystis jiroveci were also calculated. Microbiological findings were present in $87 \%$ of BALF samples. Possible infectious pathogens were detected in $55 \%$ of cases; $32 \%$ were classified as colonizing. No significant difference in diagnostic yield or pathogen spectrum was found between non-neutropenic and neutropenic patients. There was one significant difference in BALF findings among intensive care units (ICU) versus non-ICU patients for Aspergillus spp. (22\% versus $9 \%, p=0.03$ ). The most common pathogens were Aspergillus spp. ( $n=86,33 \%$ of BAL with causative pathogens) and Streptococcus pneumoniae $(n=46,18 \%)$; polymicrobial etiology was documented in $20 \%$ of cases. A quantitative PCR value of $>1860 \mathrm{cp} / \mathrm{mL}$ for Pneumocystis jirovecii was set as a diagnostic threshold for pneumocystis pneumonia. The absorbance index of GM in BALF of 0.5 was set as a diagnostic threshold for aspergillosis. The examination of BAL fluid revealed the presence of pathogen in more than $50 \%$ of cases and is, therefore, highly useful in this regard when concerning pulmonary infiltrates.
\end{abstract}

\section{Introduction}

Lower respiratory tract infections have a high morbidity and mortality in immunocompromised patients (Rano

P. Zak and E. Vejrazkova contributed equally to this work.

Electronic supplementary material The online version of this article (https://doi.org/10.1007/s12223-019-00712-4) contains supplementary material, which is available to authorized users.

Jakub Radocha

jakub.radocha@centrum.cz

1 4th Department of Internal Medicine - Hematology, University Hospital Hradec Kralove and Faculty of Medicine Hradec Kralove, Charles University, Prague, Czech Republic

2 Institute of Clinical Biochemistry and Diagnostics, University Hospital Hradec Kralove and Faculty of Medicine Hradec Kralove, Charles University, Prague, Czech Republic

3 Institute of Clinical Microbiology of University Hospital Hradec Kralove and Faculty of Medicine Hradec Kralove, Charles University, Prague, Czech Republic et al. 2001; Boersma et al. 2007; Hummel et al. 2008). The identification of the causative agents may influence previously introduced empirical antimicrobial therapy and enable the administration of a specific therapy, if at all
4 Department of Medical Microbiology of 2nd Medical Faculty of Charles University and Motol University Hospital, Charles University, Prague, Czech Republic

Department of Pneumology, University Hospital Hradec Kralove and Faculty of Medicine Hradec Kralove, Charles University, Prague, Czech Republic 
available (Oren et al. 2016; Hohenadel et al. 2001; Hummel et al. 2008).

The patients with hematological malignancies have an increased risk of opportunistic infections, such as invasive mycoses, Pneumocystis jirovecii pneumonia (PCP), or cytomegalovirus (CMV) pneumonia (Rano et al. 2001; Joos et al. 2007). Common viral infections of the upper respiratory tract have a high tendency to progress towards severe pneumonia, resulting in a high mortality rate estimated in 50-70\% of these patients. These infections are frequently associated with bacterial or fungal co-infections and/or super-infections (Chemaly et al. 2006).

The bronchoalveolar lavage (BAL) is a valuable and a uniformly accepted safe procedure (Chemaly et al. 2006; Joos et al. 2007; Kuehnhardt et al. 2009) that may identify the etiological agent of pulmonary infections. The aim of our study was to evaluate the diagnostic yield of microbiological BAL fluid (BALF) analysis in patients with malignant hematological disorders using diagnostic methods that included PCR. Furthermore, we evaluated clinically relevant cutoffs of the two most important opportunistic pathogens: Pneumocystis jirovecii DNA quantity for the diagnosis of PCP and galactomannan (GM) aspergillus index in BALF for the diagnosis of invasive aspergillosis (IA).

\section{Patients and methods}

Our retrospective study analyzed the microbiological agents detected in BALF from patients with hematological diseases and pulmonary infiltrates and whom were being treated at the 4th Department of Internal Medicine - Hematology of the University Hospital and Faculty of Medicine of Charles University at Hradec Kralove, Czech Republic, between January 2007 and December 2014. This study was reviewed and approved by the Ethics Committee of the University Hospital Hradec Kralove.

Patients with pulmonary infiltrates, confirmed by chest Xray scan and/or high-resolution computed tomography (HRCT), were indicated for bronchoscopy examination with BAL according to their clinical status. These deeply immunosuppressed patients were treated with wide spectrum antibiotics, antimycotics, and antiviral therapy according to current standards and guidelines. These included upfront combination of piperacillin/tazobactam plus levofloxacin in stable patients, meropenem instead of piperacillin/tazobactam in cases of instability or known previous colonization with bacteria resistant to piperacillin/tazobactam.

The following criteria were also included for further analysis: demographic data, underlying diseases, previous transplantation of allogeneic hematopoietic stem cells, concurrent neutropenia (neutrophil count $>1000 / \mu \mathrm{L}$ ), intensive care
(ICU), and/or mechanical ventilation necessity, as well as death caused by an underlying pulmonary pathology $<30$ days after BAL.

BAL sampling was routinely performed by experienced physicians using a fiberoptic bronchoscope (FOB, Olympus, Japan) within 1 or 2 days after HRCT (or, occasionally, chest X-ray when HRCT was not available). FOB procedures were performed at the bedside within the intensive care unit in cases of mechanically ventilated subjects (invasive or non-invasive) and under local anesthesia (lidocaine) and mild sedation (midazolam i.v.); further, platelet transfusions were administered $(>20,000 / \mu \mathrm{L})$ before FOB. All other patients underwent FOB at the bronchoscopy unit. BALFs were obtained by gently wedging the tip of the bronchoscope into the area of greatest radiographic abnormality. BAL was performed in the most severely impaired pulmonary segment/sub-segment when multiple consolidation areas were present. Each BALF aliquot consisted of $50 \mathrm{~mL}$ of sterile physiological saline pre-warmed to body temperature; the aspiration of $\mathrm{BAL}$ aliquots used very low pressure to avoid airway collapse. The BALF samples were stored in transparent plastic containers with non-adherent surfaces and immediately $(\leq 1 \mathrm{~h})$ processed in the laboratory.

The BALF samples were tested using classic microbiological cultures designed for bacteria, fungi, and mycobacteria on conventional agar media (blood agar, chocolate agar, MacConkey, and anaerobic blood agar) at $37^{\circ} \mathrm{C}$ under aerobic and anaerobic conditions, as required. All the species found in the culture isolates were identified by standard methods. The detection of Legionella pneumophila was achieved using BCYE (buffered charcoal yeast extract) medium. One of the collected BALF aliquots was processed for fungal culture (incubated on Sabouraud's agar under aerobic conditions at $30{ }^{\circ} \mathrm{C}$ for 7 days). Mycobacterium tuberculosis, and other mycobacteria, was detected through the microscopic examination of Ziehl-Neelsen-stained smears cultured under aerobic conditions at $37^{\circ} \mathrm{C}$ for 6 weeks (Ogawa, Löwenstein-Jensen) and in mycobacterial growth indicator tubes (MGIT). Pneumocystis jirovecii was detected by microscopic examination with methanol-Giemsa staining.

DNA was isolated using the QIAamp DNA Mini Kit; Tissue protocol was used for bacterial or fungi DNA, QIAamp Viral RNA Mini Kit for RNA viruses (all Qiagen, Hilden, Germany). PCR tests were partly designed and validated in-house until 2013; these included Varicella zoster virus (VZV), adenoviruses, Mycoplasma pneumoniae, Chlamydia pneumoniae, Legionella pneumophila, Pneumocystis jirovecii, Aspergillus spp., and respiratory DNA viruses (sequences are presented in Supplementary Table 1). Since 2013, commercial kits for the detection of these respiratory viruses have been available using the PCR Anyplex ${ }^{\mathrm{TM}}$ II RV 16 kit (Seegene, Inc., South Korea): 
influenza (INF) A, B, parainfluenza (PIV) 1-4, respiratory syncytial virus (RSV) $A, B$, human metapneumovirus (hMPV), human rhinovirus (HRV) $A / B / C$, human adenovirus, human coronavirus 229E, NL63, OC 43, human enterovirus, human bocavirus 1/2/3/4. The Platelia ${ }^{\circledR}$ Aspergillus EIA (Bio-Rad Laboratories, USA) immunoenzymatic sandwich microplate assay was used for detection of Aspergillus GM. The absorbance is determined with a spectrophotometer set at 450- and 620-nm wavelength. The presence of herpes simplex virus (HSV) and human cytomegalovirus (CMV) was tested using a Gene Proof system, whereas Mycobacterium tuberculosis complex and non-tuberculous mycobacteria were detected using the Anyplex MTB/NTM Real-time PCR kit (Seegene Inc., South Korea). All real-time PCR assays were performed according to the manufacturer's instructions using Rotor Gene (Qiagen, Hilden, Germany) and Light Cycler realtime PCR machines (Roche, AG, Switzerland). While the sensitivity of both techniques is comparable, the commercial methods offer a quicker analysis and reduced workload. All described PCR methods were validated annually and verified and controlled by an international system of quality control, QCMD (Quality Control for Molecular Diagnostics, Glasgow, UK). The quantitative tests express the pathogen load as number of DNA copies per milliliter of BALF $(\mathrm{cp} / \mathrm{mL})$. The limit of detection for each test was HSV type $1=213 \mathrm{cp} / \mathrm{mL}$; HSV type $2=275 \mathrm{cp} / \mathrm{mL} ; \mathrm{CMV}=100 \mathrm{cp} / \mathrm{mL}$ (equivalent of $79.4 \mathrm{IU} / \mathrm{mL})$, Pneumocystis jirovecii $=100 \mathrm{cp} / \mathrm{mL}$; Aspergillus spp. $=50 \mathrm{cp} / \mathrm{mL}$. Other tests were only qualitative, and the results were simply reported as positive/negative.

The criteria used to define the pathogenic and colonizing agents in this study were based on an expert panel discussion and previous studies and are summarized in Tables 1 and 2. The categorization method used in this study is in agreement with the updated guidelines of the German Society of Hematology and Medical Oncology (Maschmeyer et al. 2015). The clinical diagnosis of proven and probable IA was based on current European Organization for Research and Treatment of Cancer (EORTC) criteria (De Pauw et al. 2008). Each suspected case was independently reviewed by two participating physicians (JR and AZ). The threshold for GM index was determined by receiver operator curve (ROC) curve. The clinical diagnosis of PCP pneumonia was independently reviewed by two participating physicians (JR and AZ). The threshold for Pneumocystis jirovecii qPCR was determined with a ROC curve.

\section{Statistical analysis}

Descriptive statistics for demographic and baseline characteristics were summarized for all patients. The number and percentage of patients in each category were summarized for categorical variables. Categorical data was analyzed using
Table 1 Agents considered as causative pathogens

- Cultivated: Streptococcus pneumoniae, Staphylococcus aureus, Enterobacteriaceae (Escherichia coli, Enterobacter spp., Proteus spp., Klebsiella pneumoniae, Klebsiella oxytoca), non-fermenters (Pseudomonas aeruginosa, Burkholderia cepacia group, Stenotrophomonas maltophilia, Acinetobacter baumanii), Haemophilus influenzae, Legionella pneumophila, Moraxella catarrhalis (Branhamella catarrhalis), Bordetella bronchiseptica, Nocardia spp., Mycobacterium tuberculosis, Pneumocystis jirovecii, Aspergillus spp., Zygomycetes, Geotrichum clavatum

- Detection by PCR: Mycobacterium tuberculosis, Legionella pneumophila, Mycoplasma pneumoniae, Chlamydia pneumoniae, Nocardia spp., Aspergillus spp., Zygomycetes, INF, RSV, PIV, Adenoviruses, hMPV, HRV, VZV, Coronaviruses

- DNA quantity of Pneumocystis jirovecii $\geq 1450 \mathrm{cp} / \mathrm{mL}$, CMV DNA $\geq 10,000 \mathrm{cp} / \mathrm{mL}$, HSV DNA $\geq 100,000 \mathrm{cp} / \mathrm{mL}$ in BALF.

- Aspergillus $\mathrm{GM} \geq 0.5$ index in $\mathrm{BAL}$

- "Potentially relevant" non-tuberculous mycobacteria

$P C R$ polymerase chain reaction, INF influenza, $R S V$ respiratory syncytial virus, PIV parainfluenza virus, hMPV human metapneumovirus, HRV human rhinovirus, VZV varicella zoster virus, CMV cytomegalovirus, $H S V$ herpes simplex virus, DNA deoxyribonucleic acid, GM galactomannan

the chi-square test or Fisher exact test using a $2 \times 2$ contingency table. The unpaired $t$ test or non-parametric Mann-Whitney rank sum test was used for the analysis of the independent groups. $P$ values $<0.05$ were considered statistically significant. ROC curves were calculated for Pneumocystis jirovecii qPCR and GM index. The statistical analyses were performed using the software SigmaPlot for Windows, version 11.0. (Systat Software) and MedCalc v 9.5.2 (MedCalc, Belgium).

\section{Results}

A total of 480 BALF samples from 353 patients (145 females, 208 males) were analyzed. The median age at the time of BALF collection was of 61 years (range 18-81). There were 89 patients $(25.2 \%)$ with repeated BAL. Median interval between procedures was 43 days (interquartile range (IQR) 15177 days). The most common underlying diseases were nonHodgkin lymphoma and acute myeloid leukemia. Twenty-nine percent (138 samples) of BALF samples were obtained from

Table 2 Agents considered as capable of colonizing the airways

- Cultivated: viridans streptococci, gama-haemolytical streptococci, coagulase-negative staphylococci, Enterococcus spp., Neiserria spp., Corynebacterium spp., Lactobacillus spp., anaerobic bacteria (Fusobacterium spp., Peptococcus spp., Peptostreptococcus spp., Prevotella spp., Propionibacterium spp., Veilonella spp., Eubacterium limosum, Actinomyces spp.), Candida spp., and Saccharomyces

- Low quantities of Pneumocystis jirovecii DNA $<1450 \mathrm{cp} / \mathrm{mL}, \mathrm{CMV}$

DNA $<10,000 \mathrm{cp} / \mathrm{mL}$, HSV DNA $<100,000 \mathrm{cp} / \mathrm{mL}$ in BALF - Aspergillus spp. GM $<0.5$ index in $\mathrm{BAL}$

DNA deoxyribonucleic acid, CMV cytomegalovirus, GM galactomannan 
neutropenic patients, and $24 \%$ of examinations (116 BAL in 82 patients) were done in recipients of allogeneic hematopoietic stem cell transplantation (HSCT). $74.4 \%$ of patients were managed on ICU. The data concerning demographics, underlying diseases, and HSCT are summarized in Table 3. Overall pneumonia-related mortality was $25 \%$ in our cohort. Mortality related to ongoing pneumonia in our cohort was influenced by neither positive nor negative microbiological results of BAL $(p=0.82)$, nor type of agents $(p \geq 0.70)$ nor agranulocytosis $<$ $1000 / \mu \mathrm{L}(p=1)$. The only significant mortality predictor was prior HSCT ( $p=0.023)$, but it was independent on BAL results (positive versus negative microbiological results, $p=0.68$ ).

Of 480 obtained BALF samples, microorganisms were found in $87 \%$ of them. Overall, $82 \%$ of patients in ICU and $54 \%$ of non-ICU patients received previous empiric ATB treatment according to current practice described above $(p<0.0001)$. The probable infectious pathogens were detected in $55 \%$ of samples; $32 \%$ were classified as colonizing (Fig. 1). The non-infectious causes of respiratory complications were diagnosed via 33 BAL procedures $(7 \%)$. The diagnostic yield did not differ between non-neutropenic $(56 \%)$ and neutropenic $(52 \%)$ patients $(p=0.84)$; also, there was no significant difference in the pathogens detected between these two groups (bacterial $p=0.24$, fungal $p=0.40$, viral $p=$ 0.67 , monomicrobial/polymicrobial $p=0.41$ ). There were no significant differences in BALF findings among ICU versus non-ICU patients except for Aspergillus spp. where ICU patients showed higher positivity (22\% versus $9 \%, p=0.03$ ). FOB with BAL was generally well tolerated and safe, and no serious adverse reactions were observed during the procedure, where no major bleeding was observed afterwards.

The assumed causative pathogens detected are shown in Table 4, whereas the detected colonizing agents are presented in Table 5. The etiological agents of pneumonia were considered to be polymicrobial in $20 \%$ of cases; viruses and fungi occurred as co-pathogens in almost one half of occurrence cases ( $54 \%$ resp. $46 \%$ ), details in this regard are shown in Table 6 (list of specific co-pathogens is presented in Supplementary Table 2 The most common co-pathogens were Aspergillus spp. (42 cases of polymicrobial infections), Streptococcus pneumoniae $(n=23)$, Klebsiella spp. $(n=20)$, and Pseudomonas aeruginosa $(n=16)$. If multiple pathogens were found, all were treated accordingly. Four BALF samples proved positive for Mycobacterium tuberculosis, although only two were clinically relevant. Three cultures of Mycobacterium avium and 29 positive PCR results for Mycobacterium spp. (other than M. tuberculosis) were observed. Only one case met the American Thoracic Society Documents criteria of nontuberculous mycobacterial pulmonary disease (Griffith et al. 2007). This diagnosis was confirmed through lung biopsy.

Aspergillus spp. was the most common agent detected in BAL samples of both non-neutropenic $(n=52)$ and neutropenic patients $(n=34)$ in our cohort. We detected 64 cases of probable/proven IA clinical diagnosis. We analyzed the GM significance in BALF samples as well. The median absorbance (A) index of GM in the probable/proven IA group was 1.24 (range $0.24-8.80$ ) and was significantly higher $(p<0.001)$ than the median in the non-aspergillosis group
Table 3 Characteristics of the patients

\begin{tabular}{lll}
\hline & No. of patients $(n=353)$ & $\%$ \\
\hline Male & 208 & 59 \\
Female & 145 & 41 \\
Non-HSCT recipients & 271 & 77 \\
Allogeneic HSCT recipients & 82 & 23 \\
Age: median age 61 years; range 18-81 & & \\
Diagnosis & & 22 \\
Acute myeloid leukemia & 77 & 8 \\
Acute lymphoblastic leukemia & 29 & 2 \\
Chronic myeloid leukemia & 7 & 15 \\
Chronic lymphocytic leukemia/small lymphocytic lymphoma & 53 & 6 \\
Hodgkin lymphoma & 21 & 25 \\
Non-Hodgkin lymphoma & 87 & 12 \\
Multiple myeloma (and plasma cell leukemia) & 42 & 2 \\
Other hematologic malignancies (hairy cell leukemia, & 6 & 5 \\
prolymphocytic leukemia) & & 2 \\
Myelodysplastic syndrome & 17 & 1 \\
Myeloproliferative disorder, myelodysplastic/myeloproliferative neoplasm & 9 & 5 \\
Aplastic anemia & 5 & \\
\hline
\end{tabular}

HSCT hematology stem cell transplantation 
Fig. 1 Diagnostic yield. Asterisk indicates other significant findings independent on microbiological results were identified in $33 \mathrm{BAL}(7 \%)$ : Diffuse alveolar hemorrhage (DAH, 18×), tumor $(7 \times)$, bronchiolitis obliterans syndrome (BOS, $2 \times$ ), and bronchiolitis obliterans organizing pneumonia (BOOP, 1×), all probably in association with graft-versus-host disease, usual interstitial pneumonia (UIP, $3 \times$ ), chronic diffuse interstitial lung-idiopathic pulmonary fibrosis, sarcoidosis

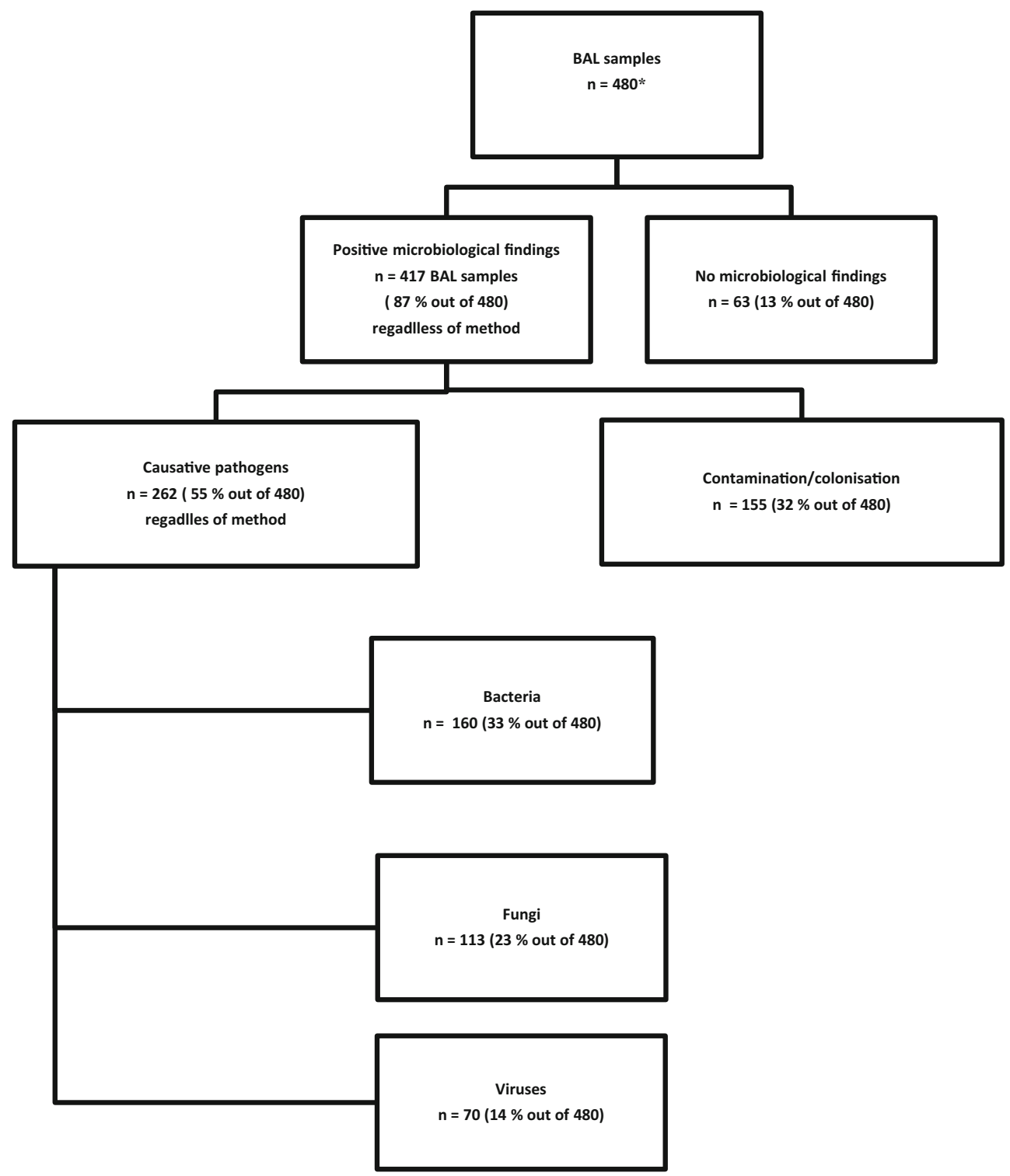

(0.28; range 0.14-0.6). The area under the ROC curve (AUC) for $\mathrm{BAL} G M \geq 0.5 \mathrm{~A}$ index was 0.972 (95\% CI 0.922-0.994), see Fig. 2.

There were a total of $42 P$. jirovecii DNA positive BAL samples (median $6680 \mathrm{cp} / \mathrm{mL}$, range 138-94,300,000 cp/mL). The clinical presentation, quantity of $P$. jirovecii DNA copies in BAL samples, and radiographic presentation were general triggers for specific PCP treatment in 26 patients (see Fig. 3). The median DNA quantity in BALF samples among the PCP patients' group was $12,700 \mathrm{cp} / \mathrm{mL}$ (range 600-94,300,000), which was significantly higher $(p<0.001)$ when compared to the non-PCP group (680 cp/mL, range 144-6680). Subsequently, $1860 \mathrm{cp} / \mathrm{ml}$ was calculated as a threshold associated with PCP diagnosis, showing an excellent sensitivity of 91\% (95\% confidence interval (CI) 76.3-98.0) and specificity $96 \%$ (95\% CI 78.8-99.3). The area under the ROC curve
(AUC) for this threshold was 0.95 (95\% CI 0.851 to 0.987 ), see Fig. 4.

\section{Discussion}

Microorganisms were detected in $87 \%$ of the analyzed BALF samples. This is slightly higher than in previous recent reports which were able to detect them in only $50-73 \%$ of samples (Bissinger et al. 2005; Kim et al. 2015; Hardak et al. 2016). This difference could be due to the wider range of microorganisms included in our standard BALF detection. It is important to point out that the majority of BAL procedures were done after initiation of ATB treatment $(82 \%$ of ICU patients and $54 \%$ of non-ICU patients), which is similar to situation in other reports and centers (Rano et al. 2001; Boersma et al. 
Table 4 Causative pathogens

\begin{tabular}{|c|c|c|c|c|c|c|}
\hline & & & $\begin{array}{l}\text { Positive hits in BALF } \\
\text { (regardless of method) }\end{array}$ & Cultivated & PCR & Other \\
\hline \multirow[t]{16}{*}{ Bacteria } & \multirow[t]{7}{*}{ Enterobacteriaceae } & Klebsiella pneumoniae & 27 & 27 & - & - \\
\hline & & Klebsiella oxytoca & 6 & 6 & - & - \\
\hline & & Escherichia coli & 24 & 24 & - & - \\
\hline & & Enterobacter spp. & 11 & 11 & - & - \\
\hline & & Acinetobacter spp. & 7 & 7 & - & - \\
\hline & & Stenotrophomonas maltophilia & 6 & 6 & - & - \\
\hline & & Proteus spp. & 5 & 5 & - & - \\
\hline & \multirow[t]{2}{*}{ Non-fermenters } & Pseudomonas aeruginosa & 30 & 30 & - & - \\
\hline & & Burkholderia cepacia group & 14 & 14 & - & - \\
\hline & Streptococcus pneumoniae & & 46 & 0 & 45 & 2 (microscopy) \\
\hline & Staphylococcus aureus & & 10 & 10 & - & - \\
\hline & Haemophilus influenza & & 6 & 6 & - & - \\
\hline & Legionella pneumophila & & 5 & 1 & 5 & - \\
\hline & Mycobacterium tuberculosis & & 4 & 2 & 4 & - \\
\hline & Mycobacterium avium & & 1 & 1 & 1 & - \\
\hline & $\begin{array}{l}\text { Other bacterial pathogens } \\
\text { (Moraxella catarrhalis, Bordete } \\
\quad \text { Nocardia } \text { species) }\end{array}$ & lla bronchiseptica, & 4 & 4 & 1 (Nocardia spp.) & - \\
\hline \multirow[t]{4}{*}{ Fungi } & Aspergillus spp. & & $86^{\mathrm{a}}$ & 8 & $45^{\mathrm{a}}$ & $62^{\mathrm{b}}$ \\
\hline & Pneumocystis jirovecii & & $28^{\mathrm{a}}$ & - & $28^{\mathrm{a}}$ & - \\
\hline & Zygomycetes & & 6 & 2 & 6 & - \\
\hline & Geotrichum clavatum & & 1 & 1 & - & - \\
\hline \multirow[t]{10}{*}{ Viral } & \multirow[t]{7}{*}{ Community respiratory viruses } & Respiratory syncytial virus & 19 & - & 19 & - \\
\hline & & Influenza virus & 13 & - & 13 & - \\
\hline & & Parainfluenza virus & 5 & - & 5 & - \\
\hline & & Rhinovirus & 12 & - & 12 & - \\
\hline & & Adenovirus & 11 & - & 11 & - \\
\hline & & Human metapneumovirus & 3 & - & 3 & - \\
\hline & & Coronavirus & 1 & - & 1 & - \\
\hline & \multirow[t]{3}{*}{ Herpes viruses } & Herpes simplex virus ${ }^{\mathrm{a}}$ & $1^{\mathrm{a}}$ & - & $1^{\mathrm{a}}$ & - \\
\hline & & Human cytomegalovirus $^{\mathrm{a}}$ & $9^{\mathrm{a}}$ & - & $9^{\mathrm{a}}$ & - \\
\hline & & Varicella zoster virus & 3 & - & 1 & - \\
\hline
\end{tabular}

a qPCR in "significant quantities": Pneumocystis jirovecii $\geq 1450 \mathrm{cp} / \mathrm{mL}$, human cytomegalovirus $\geq 10,000 \mathrm{cp} / \mathrm{mL}$, herpes simplex virus $\geq 100,000 \mathrm{cp} / \mathrm{mL}$

${ }^{\mathrm{b}}$ Aspergillus GM BAL $\geq 0.5$ index

2007; Hummel et al. 2008; Kuehnhardt et al. 2009); therefore, our results could be negatively influenced by any ongoing antimicrobial treatment, resulting in lower diagnostic yield in BALF cultures (Kuehnhardt et al. 2009).

Potential infectious pathogens were detected in $55 \%$ of BAL samples. Other published studies report this value in $25-50 \%$. An accurate comparison of various reports is somewhat complicated by the heterogeneity of laboratory methods (e.g., conventional culture versus molecular methods), different definitions of pathogens, patient cohorts, and prior ATB treatment (Hohenadel et al. 2001; Rano et al. 2001; Boersma et al. 2007; Maschmeyer et al. 2015). We assume that our slightly higher detection rate of potential pathogens is related to the combination of different diagnostic techniques in one sample, including molecular biology methods. Two recent studies (Tang et al. 2018; Oren et al. 2016) using molecular analysis proved infectious ethology of pneumonia in $49-63 \%$ of BAL procedures, which is similar to our study.

There was no statistical difference in pathogen detection between BAL samples from neutropenic $(52 \%)$ and nonneutropenic $(56 \%)$ cohorts; similar results were also reported by other authors (Cordonnier et al. 1994; Kuehnhardt et al. 2009). The relatively minor difference between both groups might be attributed to the fact that these non-neutropenic patients were immunocompromised; further, most of them had undergone chemotherapy and had previous episodes of 
Table 5 Colonizing agents

\begin{tabular}{llll}
\hline Colonization & Cultivation & PCR & Other \\
\hline Streptococcus viridans & 133 & - & - \\
Coagulase-negative staphylococci & 141 & - & - \\
Enterococcus spp. & 146 & - & - \\
Neisseria spp. & 10 & - & - \\
Other bacterial contamination & 16 & - & - \\
(other streptococci, corynebacteria, lactobacilli) & & $28^{\mathrm{a}}$ & - \\
Non-tuberculous mycobacteria & $2^{\mathrm{a}}$ & - & - \\
Anaerobic bacteria & 75 & - & - \\
Candida albicans & 29 & - & - \\
Non-albicans Candida & 42 & - & - \\
Saccharomyces cerevisiae & 8 & - & $61^{\mathrm{c}}$ \\
Aspergillus spp. & - & $14^{\mathrm{b}}$ & - \\
Pneumocystis jirovecii & - & $42^{\mathrm{b}}$ & - \\
Human cytomegalovirus & - & $67^{\mathrm{b}}$ & - \\
Herpes simplex virus & - & & \\
\hline
\end{tabular}

${ }^{a}$ The criterion of non-tuberculous pulmonary disease was not fulfilled in any case

${ }^{\mathrm{b}}$ qPCR in "non-significant quantities": Pneumocystis jirovecii $<1450 \mathrm{cp} / \mathrm{mL}$, human cytomegalovirus $<10,000$ $\mathrm{cp} / \mathrm{mL}$, herpes simplex virus $<100,000 \mathrm{cp} / \mathrm{mL}$

${ }^{\mathrm{c}}$ Aspergillus GM BAL $<0.5$ index

neutropenia, even if they were non-neutropenic at the time of BAL collection (Kuehnhardt et al. 2009). Detection of Aspergillus spp. (by any method) was more frequent in ICU patients. The fact that Aspergillus is a common finding in BALF of ICU patients has been previously reported (Zarrinfar et al. 2013; Khodavaisy et al. 2015) and might be the reflection of the overall severity of ICU patients.

The etiological agents of pneumonia were considered polymicrobial in $20 \%$ of our cases. The incidence of pulmonary polymicrobial infections in patients with hematological malignancies and pulmonary infiltrates can vary from 20 to 60\% (Rolston et al. 2007; Hardak et al. 2016). This wide range is likely due to different definitions for bacterial and viral pneumonia, as well as differences in laboratory methods. An Israel study (Oren et al. 2016) that included PCR methods reported the same proportion of polymicrobial pneumonia

Table 6 Polymicrobial infections

\begin{tabular}{ll}
\hline Polymicrobial infections & No. of BAL $(n=480)$ \\
\hline Total & $98(20 \%)$ \\
Polybacterial infections & 19 \\
Mixed fungal infections & 2 \\
Polyviral infections & 4 \\
Bacteria plus fungi & 35 \\
Bacteria plus virus & 21 \\
Fungi plus virus & 9 \\
Bacteria plus fungi plus virus & 8 \\
\hline
\end{tabular}

(21\%) in similar patients' cohort. A recent Beijing study (Tang et al. 2018) using various flexible bronchoscopy methods determined the polymicrobial etiology in $47 \%$ of cases. Contrasting to our work, this work also described viruses as the most common infectious etiology of pneumonia (70\%). These results were influenced by their patients' cohort (allogeneic HSCT recipients only), different definition of the

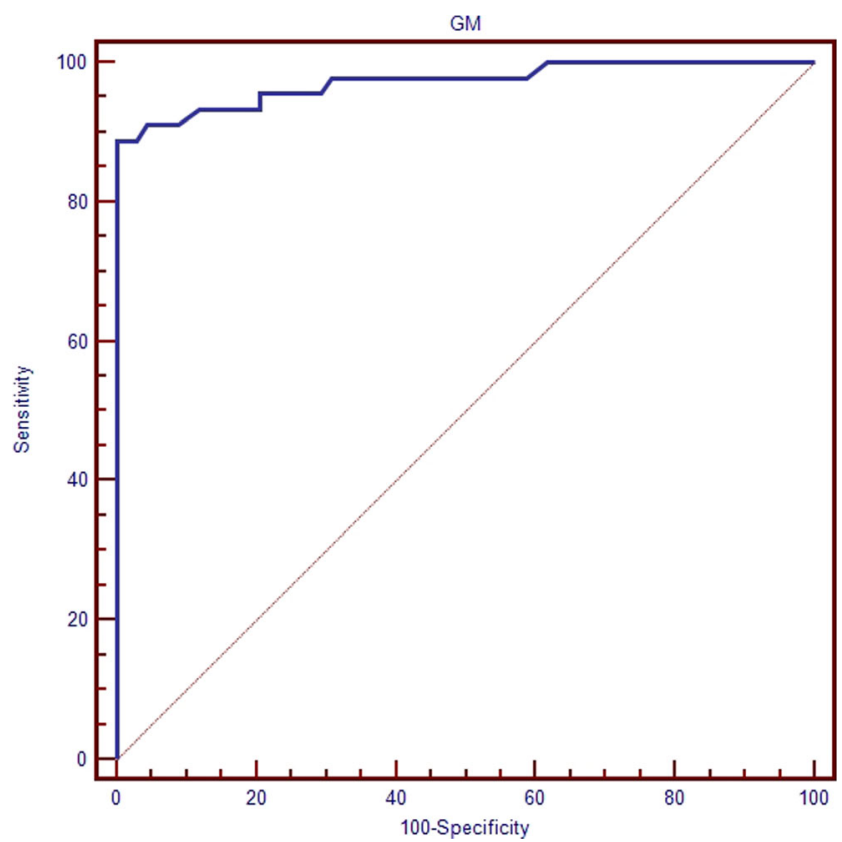

Fig. 2 ROC curve for Aspergillus galactomannan (GM) BAL $\geq 0.5$ index in probable/proven invasive aspergillosis 


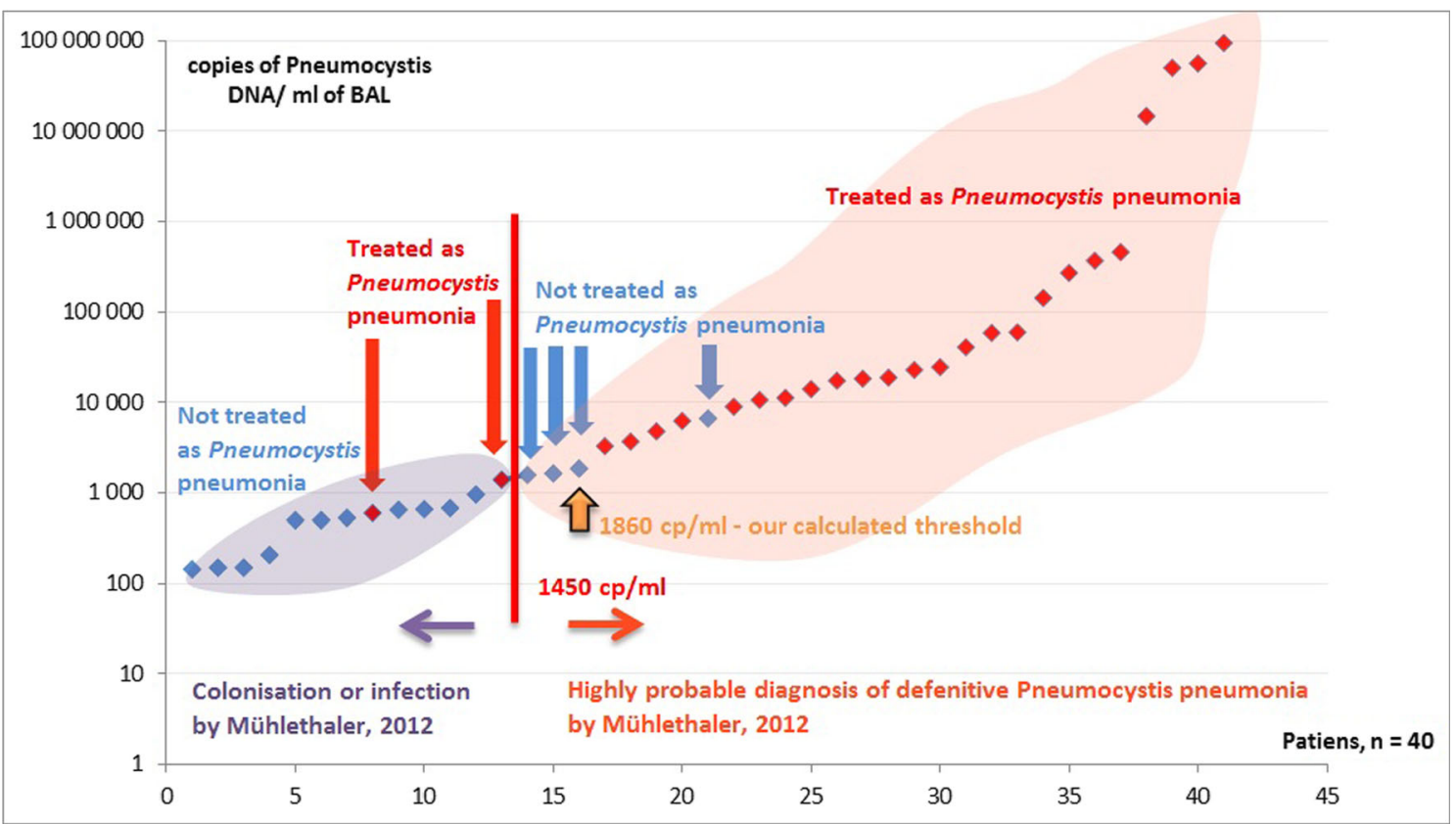

Fig. 3 Pneumocystis pneumonia. The threshold value is set based on Maertens et al. (2007)

infectious pneumonia as well as different PCR diagnostic criteria (much lower cutoff for significant PCR DNA CMV quantity in BALF and larger diagnostic spectrum including of EBV, polyomavirus, and others). Another work focusing on HSCT recipients admitted to the ICU described the polymicrobial findings in $30 \%$ of patients and worked with results from blood cultures, low PCR DNA CMV cutoff and serum GM. All these differences explain higher reported percentage of polymicrobial etiology of pneumonia.

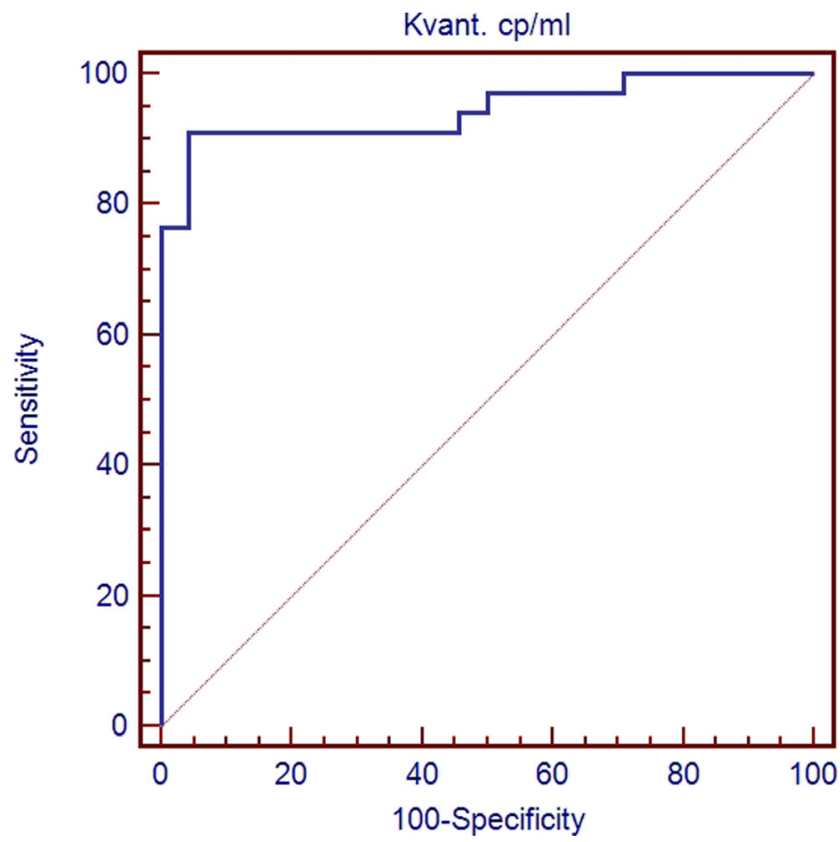

Fig. 4 ROC curve showing Pneumocystis jirovecii DNA $>1860 \mathrm{cp} / \mathrm{mL}$
Our categorization into pathogenic/colonizing agents is aligned with the updated guidelines of the German Society of Hematology and Medical Oncology (Maschmeyer et al. 2015). The microbiological agents isolated from BALF samples are not always relevant for etiology of pulmonary infiltrates and should therefore be interpreted critically (Maschmeyer et al. 2015). We report coagulase-negative staphylococci, alpha-hemolytic streptococci, and enterococci as the most common bacteria found in BALF samples, same as with other authors (Eriksson et al. 1996; Kuehnhardt et al. 2009). The significance of these organisms obtained from BAL samples remains unclear as most of them occur as commensals and rarely cause pneumonia (Kuehnhardt et al. 2009). However, some authors suggest that immunocompromised patients can develop pneumonia from these agents regardless (Kuehnhardt et al. 2009). All of these bacteria are abundant in mouth or oropharynx and can adhere to the bronchoscope during examination; therefore, we considered them as contaminating/colonizing agents. In similar manner, detected anaerobic bacteria were considered to be contamination from the oral flora since none of our patients had a lung abscess.

Streptococcus pneumoniae was the second most frequent pathogen after Aspergillus spp. based on PCR detection. $S$. pneumoniae is one of the most common causes of pneumonia in general population (Stralin et al. 2006; Murdoch et al. 2003; Falguera et al. 2002). Its prevalence in immunosuppressed patients is high (Kumar et al. 2008; Torda et al. 2014; Wieruszewski et al. 2018; Kumar et al. 2007). S. pneumoniae detection rate by conventional diagnostic methods is low, especially in cases when antibiotic therapy had been administrated before examination (Strålin et al. 2006; Smith et al. 2003; Yu 
et al. 2003). PCR detection methods may therefore be useful. However, these have relatively low specificity and positive predictive value for $S$. pneumoniae when used for non-sterile material such as BALF. This may have inflated the incidence rates in our cohort.

Aspergillus spp. was the most commonly detected agent in our study, which is consistent with the reports from other authors (Oren et al. 2016; Tang et al. 2018; Rano et al. 2001; Boersma et al. 2007; Hardak et al. 2016). We set the cutoff value to 0.5 for the BAL GM A index, obtaining excellent specificity and sensitivity; this is consistent with studies by Bergeron et al. (2010) and Maertens et al. (2007).

Zygomycosis, the second most frequently detected filamentous fungi, has recently been described as one of the most common type of mycosis reported in patients with hematological malignancies, particularly in acute leukemia patients or HSCT recipients (Caira et al. 2010; Cuenca-Estrella et al. 2009). We observed six positive qPCR hits for Zygomycetes in this study; all six patients were treated for zygomycosis, as they were high-risk patients with clinical signs consistent with invasive fungal disease. Two of these qPCR hits were also confirmed by BAL culture, meeting the criteria for "probable" fungal disease as per EORTC criteria (De Pauw et al. 2008). The remaining four were classified as "possible." The histopathological confirmation of invasive zygomycosis is required (Siwek et al. 2004; Stelzmueller et al. 2008); however, none was available in our patients. Despite our awareness of a potentially high false positivity rate, we firmly believe that the use of qPCR testing should be considered for Zygomycetes as one of the diagnostic criteria.

We calculated the threshold for qPCR detection of $P$. jirovecii, estimating a cutoff value of $1860 \mathrm{cp} / \mathrm{mL}$. Our value obtained by retrospective analysis of patients with hematological malignancies corresponds to the more heterogeneous immunocompromised patient cohort reported by Mühlethaler et al. (2012).

It must be highlighted that these PCR values can vary significantly among centers due to the different procedures for sample collection, different qPCR kits, primers, and calibrations curves. Therefore, the value cannot be directly applied at other centers with different setups. This is one of the largest studies establishing the cutoffs of Aspergillus GM and PCR PCP dealing with large cohort of real world patients and therefore confirming the clinical values of cutoffs.

The prophylaxis of HSV infection with acyclovir has contributed to a currently decreased prevalence of HSV pneumonitis in high-risk patients (Azoulay 2011). Evidence of HSV qPCR hits was observed in only $14 \%$ of BAL samples, which is similar to the $19 \%$ reported by Gooskens et al. (2007). The diagnosis of HSV pneumonia needs to be confirmed by isolating the virus from respiratory secretions, either BALF samples or lung tissue, and by demonstrating viral cytopathic effects through histopathology (Azoulay 2011). Molecular detection techniques may be too sensitive and detect HSV in the lungs of asymptomatic individuals (Gooskens et al. 2007; Agusti and Torres 2009). Oral contamination following mucosal reactivation may also play a role in HSV detection in BALF samples (Gooskens et al. 2007). A clinically relevant DNA threshold in BAL samples has not been determined and differs according to the referred study (Gooskens et al. 2007; Linssen et al. 2008). We concluded that published quantities are comparable to $100,000 \mathrm{cp} / \mathrm{mL}$ in BALF samples; therefore, this value was used as our threshold to determine significance. Regardless, no conclusive data was found to prove that this is the best possible value; thus, more studies would be needed to determine specific qPCR thresholds for HSV in BAL samples.

The detection rate of CMV (any positivity in BAL) was of $10 \%$ in our study, which did not differ from Joos et al. (2007) or Kuehnhardt et al. (2009); however, our diagnostic methods were different. Evidence of CMV DNA in BAL samples has low positive predictive value (Boeckh 2011; Maschmeyer et al. 2015). In this regard, viral load in BAL samples and their association with CMV pneumonitis in solid organ transplant recipients were studied with contradictory results (Tan et al. 2016). We could not correlate viral load with CMV pneumonia itself (defined by Ljungman et al. (2002)), as the final diagnosis was not confirmed for any cases in our cohort. Based on an expert panel discussion, $\geq 10,000 \mathrm{cp}$ CMV DNA/ $\mathrm{mL}$ per BALF sample was considered clinically significant. All patients with such CMV DNA quantity in their BALF samples had generally lower $(100 \mathrm{cp} / \mathrm{mL})$ or negative viral load in peripheral blood at the time of BAL collection.

Although pneumonia with detected human rhinoviruses (HRV) infection was reported in immunocompromised patients as well, it is still uncertain whether rhinoviruses are actually the primary cause of pneumonia or only lead to pulmonary injury and/or superinfection (Malcolm et al. 2001; Chemaly et al. 2006; Parody et al. 2007). Malcolm et al. (2001) and Parody et al. (2007) mentioned the common appearance of picornaviruses with other ongoing co-pathogens. Eight of our $12 \mathrm{HRV}$ findings were associated with other co-pathogens as well: bacteria, viruses, or aspergilli. However, all the results in our study are based only on the qPCR method in BALF samples, so the real significance of this finding remains unclear.

The observed pneumonia mortality rate in our study was of $25 \%$. Hardak et al. (2016) referred the same overall value in-hospital mortality rate as us; however, the mortality of patients with polymicrobial pneumonia was higher than of those with monomicrobial infection (49\% versus $19 \%$ ), which is contrary to our observation. Our patient cohorts were similar, but the strict criteria used in the definition of bacterial or viral pneumonia in Hardak's work may have played a crucial role in the observed difference. On the other hand, Kuehnhardt et al. (2009) reported only $16 \%$ mortality related to pneumonia. Their cohort of 58 examinations contained 2 allogenic HSCT recipients, 
compared to our 82 , which may explain the mortality difference. Multiple factors contribute to the high mortality and morbidity of HSCT recipients with pulmonary complications, e.g., T and $\mathrm{B}$ cell status and reconstitution after HSCT, immunosuppressive therapy, degree of neutropenia, presence and grade of graft versus host disease and its treatment, and status of the hematological disease at the time of HSCT.

The retrospective character of our work allowed a large patient cohort, but it is also a drawback. Some BALF results can be available as quickly as in a few hours (direct microscopy examination, some PCR methods), some can take up to days to weeks (e.g. 7 days for fungal culture, up to 6 weeks for mycobacteria cultivation). It is impossible in retrospective work to find out whether a change of antimicrobial treatment was based mainly on BAL results or on a change of patient's clinical status along with other examinations results. Hence, we analyzed the most important unbiased outcome: mortality. It remains undetermined whether acting on BALF results reduces mortality rates. Mortality related to ongoing pneumonia in our cohort was not influenced by positive nor negative microbiological results of BAL, nor type of agents or agranulocytosis $<1000 / \mu \mathrm{L}$. The only significant mortality predictor was prior HSCT $(p=0.023)$, but it was independent on BAL results. A Beijing work (Tang et al. 2018) studying an impact of flexible bronchoscopy in patients after allogeneic HSCT showed no difference in 30-day mortality between patients in positive and negative FB groups. Rano et al. (2001) demonstrated a decreased mortality rate if treatment was adjusted as soon as possible based on the results from early diagnostics combining several methods, including BAL. Another study (Kuehnhardt et al. 2009) described the change in antibiotic treatment based on BAL results in a minority of patients with no difference in mortality rate.

Several limitations of our study should be noted. First, the retrospective design and collection of clinical data from a large cohort of patients did not allow us to accurately comment in detail on parameters such as antimicrobial treatment. Blood count was only available at the day of BAL collection, and we could not evaluate the impact of potentially prolonged neutropenia (Kuehnhardt et al. 2009). An important limitation is also the lack of histological evidence supporting the specific type of pneumonia (e.g., IA, PCP).

\section{Conclusion}

In summary, BALF examination can reveal the infectious etiology of pneumonia in more than $50 \%$ of patients with hematologic malignancies, contributing key findings for individual cases (especially when a specific treatment may be administered). Up to one third of cases were classified as colonization, and $7 \%$ as a non-infectious disease. More studies are still needed to determine specific qPCR thresholds for opportunistic pathogens in BAL.

Authors contributions PZ collected and interpreted the data and wrote the manuscript. EV collected and interpreted the data and wrote the manuscript. LP performed the PCR analysis, collected and interpreted data, and reviewed and approved the manuscript. VK performed BAL procedures, wrote manuscript, and reviewed and approved the manuscript. PH interpreted the data and reviewed and approved the manuscript. MK interpreted data and reviewed and approved the manuscript. VS performed the microbiological analysis, collected and interpreted the data, and reviewed and approved the manuscript. LR performed the microbiological analysis, collected and interpreted the data, and reviewed and approved the manuscript. AZ collected and interpreted data and reviewed and approved the manuscript. PP performed the microbiological analysis, collected and interpreted data, and reviewed and approved the manuscript. JR wrote and finalized manuscript, collected and interpreted data, and is the corresponding author.

Funding information The work was supported by the project PROGRES Q40/08 (Charles University, Faculty of Medicine in Hradec Králové) and by the Czech Health Research Council, Ministry of Health of the Czech Republic, grant no. 17-28539A and MH CZ-DRO (UHHK, 00179906). The authors wish to thank Dr. Daniel Díaz, Ph.D. for his kind assistance in English language proofreading.

Compliance with ethical standards This study was reviewed and approved by the Ethics Committee of the University Hospital Hradec Kralove.

Conflict of interest The authors declare that they have no conflict of interest.

\section{References}

Agusti C, Torres A (2009) Pulmonary infection in the immunocompromised patient: strategies for management. Wiley, Chichester

Azoulay E (2011) Pulmonary involvement in patients with hematological malignancies. Springer-Verlag, Berlin

Bergeron A, Belle A, Sulahian A, Lacroix C, Chevret S, Raffoux E, Arnulf B, Socié G, Ribaud P, Tazi A (2010) Contribution of galactomannan antigen detection in BAL to the diagnosis of invasive pulmonary aspergillosis in patients with hematologic malignancies. Chest 137:410-415. https://doi.org/10.1378/chest.09-0701

Bissinger AL, Einsele H, Hamprecht K, Schumacher U, Kandolf R, Loeffler J, Aepinus C, Bock T, Jahn G, Hebart H (2005) Infectious pulmonary complications after stem cell transplantation or chemotherapy: diagnostic yield of bronchoalveolar lavage. Diagn Microbiol Infect Dis 52:275-280. https://doi.org/10.1016/j. diagmicrobio.2005.03.005

Boeckh M (2011) Complications, diagnosis, management, and prevention of CMV infections: current and future. ASH Educ Program Book 2011:305-309. https://doi.org/10.1182/asheducation-2011.1.305

Boersma WG, Erjavec Z, van der Werf TS, de Vries-Hosper HG, Gouw ASH, Manson WL (2007) Bronchoscopic diagnosis of pulmonary infiltrates in granulocytopenic patients with hematologic malignancies: BAL versus PSB and PBAL. Respir Med 101:317-325. https:// doi.org/10.1016/j.rmed.2006.04.021

Caira M, Mancinelli M, Leone G et al (2010) Invasive zygomycosis following hematopoietic stem cell transplantation. J Invasive Fungal Infect 4:47-53 
Chemaly RF, Ghosh S, Bodey GP, Rohatgi N, Safdar A, Keating MJ, Champlin RE, Aguilera EA, Tarrand JJ, Raad II (2006) Respiratory viral infections in adults with hematologic malignancies and human stem cell transplantation recipients: a retrospective study at a major cancer center. Medicine (Baltimore) 85:278-287. https://doi.org/10. 1097/01.md.0000232560.22098.4e

Cordonnier C, Escudier E, Verra F, Brochard L, Bernaudin JF, FleuryFeith J (1994) Bronchoalveolar lavage during neutropenic episodes: diagnostic yield and cellular pattern. Eur Respir J 7:114-120

Cuenca-Estrella M, Bernal-Martinez L, Isla G, Gomez-Lopez A, AlcazarFuoli L, Buitrago MJ (2009) Incidence of zygomycosis in transplant recipients. Clin Microbiol Infect 15:37-40. https://doi.org/10.1111/j. 1469-0691.2009.02978.x

De Pauw B, Walsh TJ, Donnelly JP et al (2008) Revised definitions of invasive fungal disease from the European Organization for Research and Treatment of Cancer/Invasive Fungal Infections Cooperative Group and the National Institute of Allergy and Infectious Diseases Mycoses Study Group (EORTC/MSG) Consensus Group. Clin Infect Dis 46:1813-1821. https://doi.org/ $10.1086 / 588660$

Eriksson B-M, Dahl H, Wang F-Z, Elvin K, Hillerdal G, Lundholm M, Linde A, Olding-Stenkvist E (1996) Diagnosis of pulmonary infections in immunocompromised patients by fiber-optic bronchoscopy with bronchoalveolar lavage and serology. Scand J Infect Dis 28: 479-485. https://doi.org/10.3109/00365549609037944

Falguera M, López A, Nogués A, Porcel JM, Rubio-Caballero M (2002) Evaluation of the polymerase chain reaction method for detection of Streptococcus pneumoniae DNA in pleural fluid samples. Chest 122:2212-2216

Gooskens J, Templeton KE, Claas EC, Templeton KE, Claas EC, van Bussel MJ, Smit VT, Kroes AC (2007) Quantitative detection of herpes simplex virus DNA in the lower respiratory tract. J Med Virol 79:597-604. https://doi.org/10.1002/jmv.20861

Griffith DE, Aksamit T, Brown-Elliott BA, Catanzaro A, Daley C, Gordin F, Holland SM, Horsburgh R, Huitt G, Iademarco MF, Iseman M, Olivier K, Ruoss S, von Reyn CF, Wallace RJ Jr, Winthrop K (2007) An official ATS/IDSA statement: diagnosis, treatment, and prevention of nontuberculous mycobacterial diseases. Am J Respir Crit Care Med 175:367-416. https://doi.org/10.1164/rccm.200604571ST

Hardak E, Avivi I, Berkun L, Raz-Pasteur A, Lavi N, Geffen Y, Yigla M, Oren I (2016) Polymicrobial pulmonary infection in patients with hematological malignancies: prevalence, co-pathogens, course and outcome. Infection 44:491-497. https://doi.org/10.1007/s15010016-0873-3

Hohenadel IA, Kiworr M, Genitsariotis R, Zeidler D, Lorenz J (2001) Role of bronchoalveolar lavage in immunocompromised patients with pneumonia treated with a broad spectrum antibiotic and antifungal regimen. Thorax 56:115-120

Hummel M, Rudert S, Hof H, Hehlmann R, Buchheidt D (2008) Diagnostic yield of bronchoscopy with bronchoalveolar lavage in febrile patients with hematologic malignancies and pulmonary infiltrates. Ann Hematol 87:291-297. https://doi.org/10.1007/s00277007-0391-6

Joos L, Chhajed PN, Wallner J, Battegay M, Steiger J, Gratwohl A, Tamm M (2007) Pulmonary infections diagnosed by BAL: a 12year experience in 1066 immunocompromised patients. Respir Med 101:93-97. https://doi.org/10.1016/j.rmed.2006.04.006

Khodavaisy S, Hedayati MT, Alialy M et al (2015) Detection of galactomannan in bronchoalveolar lavage of the intensive care unit patients at risk for invasive aspergillosis. Curr Med Mycol 1:12-17. https://doi.org/10.18869/acadpub.cmm.1.1.12

Kim SW, Rhee CK, Kang HS, Lee HY, Kang JY, Kim SJ, Kim SC, Lee SY, Kim YK, Lee JW (2015) Diagnostic value of bronchoscopy in patients with hematologic malignancy and pulmonary infiltrates.
Ann Hematol 94:153-159. https://doi.org/10.1007/s00277-0142172-3

Kuehnhardt D, Hannemann M, Schmidt B, Heider U, Possinger K, Eucker J (2009) Therapeutic implication of BAL in patients with neutropenia. Ann Hematol 88:1249-1256. https://doi.org/10.1007/ s00277-009-0747-1

Kumar D, Humar A, Plevneshi A, Green K, Prasad GVR, Siegal D, the Toronto Invasive Bacterial Diseases Networke, McGeer A (2007) Invasive pneumococcal disease in solid organ transplant recipients10-year prospective population surveillance. Am J Transplant 7: 1209-1214. https://doi.org/10.1111/j.1600-6143.2006.01705.x

Kumar D, Humar A, Plevneshi A et al (2008) Invasive pneumococcal disease in adult hematopoietic stem cell transplant recipients: a decade of prospective population-based surveillance. Bone Marrow Transplant 41:743-747. https://doi.org/10.1038/sj.bmt.1705964

Linssen CFM, Jacobs JA, Stelma FF, van Mook WNKA, Terporten P, Vink C, Drent M, Bruggeman CA, Smismans A (2008) Herpes simplex virus load in bronchoalveolar lavage fluid is related to poor outcome in critically ill patients. Intensive Care Med 34:2202-2209. https://doi.org/10.1007/s00134-008-1231-4

Ljungman P, Griffiths P, Paya C (2002) Definitions of cytomegalovirus infection and disease in transplant recipients. Clin Infect Dis 34: 1094-1097. https://doi.org/10.1086/339329

Maertens JA, Klont R, Masson C, Theunissen K, Meersseman W, Lagrou K, Heinen C, Crepin B, Eldere JV, Tabouret M, Donnelly JP, Verweij PE (2007) Optimization of the cutoff value for the aspergillus double-sandwich enzyme immunoassay. Clin Infect Dis 44: 1329-1336. https://doi.org/10.1086/514349

Malcolm E, Arruda E, Hayden FG, Kaiser L (2001) Clinical features of patients with acute respiratory illness and rhinovirus in their bronchoalveolar lavages. J Clin Virol 21:9-16. https://doi.org/10.1016/ S1386-6532(00)00180-3

Maschmeyer G, Carratalà J, Buchheidt D, Hamprecht A, Heussel CP, Kahl C, Lorenz J, Neumann S, Rieger C, Ruhnke M, Salwender H, Schmidt-Hieber M, Azoulay E, Infectious Diseases Working Party of the German Society of Hematology and Medical Oncology (2015) Diagnosis and antimicrobial therapy of lung infiltrates in febrile neutropenic patients (allogeneic SCT excluded): updated guidelines of the Infectious Diseases Working Party (AGIHO) of the German Society of Hematology and Medical Oncology (DGHO). Ann Oncol 26:21-33. https://doi.org/10.1093/annonc/ mdu192

Mühlethaler K, Bögli-Stuber K, Wasmer S, von Garnier C, Dumont P, Rauch A, Mühlemann K, Garzoni C (2012) Quantitative PCR to diagnose Pneumocystis pneumonia in immunocompromised nonHIV patients. Eur Respir J 39:971-978. https://doi.org/10.1183/ 09031936.00095811

Murdoch DR, Anderson TP, Beynon KA, Chua A, Fleming AM, Laing RTR, Town GI, Mills GD, Chambers ST, Jennings LC (2003) Evaluation of a PCR assay for detection of Streptococcus pneumoniae in respiratory and nonrespiratory samples from adults with community-acquired pneumonia. J Clin Microbiol 41:63-66

Oren I, Hardak E, Zuckerman T, Geffen Y, Hoffman R, Yigla M, Avivi I (2016) Does molecular analysis increase the efficacy of bronchoalveolar lavage in the diagnosis and management of respiratory infections in hemato-oncological patients? Int J Infect Dis 50:48-53. https://doi.org/10.1016/j.ijid.2016.07.011

Parody R, Rabella N, Martino R, Otegui M, del Cuerpo M, Coll P, Sierra J (2007) Upper and lower respiratory tract infections by human enterovirus and rhinovirus in adult patients with hematological malignancies. Am J Hematol 82:807-811. https://doi.org/10.1002/ajh. 20974

Rano A, Agusti C, Jimenez P et al (2001) Pulmonary infiltrates in nonHIV immunocompromised patients: a diagnostic approach using non-invasive and bronchoscopic procedures. Thorax 56:379-387. https://doi.org/10.1136/thorax.56.5.379 
Rolston KVI, Bodey GP, Safdar A (2007) Polymicrobial infection in patients with cancer: an underappreciated and underreported entity. Clin Infect Dis 45:228-233. https://doi.org/10.1086/518873

Siwek GT, Dodgson KJ, de Margarida M-S et al (2004) Invasive zygomycosis in hematopoietic stem cell transplant recipients receiving voriconazole prophylaxis. Clin Infect Dis 39:584-587. https:// doi.org/10.1086/422723

Smith MD, Derrington P, Evans R, Creek M, Morris R, Dance DAB, Cartwright K (2003) Rapid diagnosis of bacteremic pneumococcal infections in adults by using the Binax NOW Streptococcus pneumoniae urinary antigen test: a prospective, controlled clinical evaluation. J Clin Microbiol 41:2810-2813

Stelzmueller I, Lass-Floerl C, Geltner C, Graziadei I, Schneeberger S, Antretter H, Mueller L, Zelger B, Singh N, Pruett TL, Margreiter $\mathrm{R}$, Bonatti H (2008) Zygomycosis and other rare filamentous fungal infections in solid organ transplant recipients. Transpl Int 21:534 546. https://doi.org/10.1111/j.1432-2277.2008.00657.x

Strålin K, Korsgaard J, Olcén P (2006) Evaluation of a multiplex PCR for bacterial pathogens applied to bronchoalveolar lavage. Eur Respir J 28:568-575. https://doi.org/10.1183/09031936.06.00006106

Tan SK, Burgener EB, Waggoner JJ, Gajurel K, Gonzalez S, Chen SF, Pinsky BA (2016) Molecular and culture-based bronchoalveolar lavage fluid testing for the diagnosis of cytomegalovirus pneumonitis. Open Forum Infect Dis 3. https://doi.org/10.1093/ofid/ofv212

Tang F-F, Zhao X-S, Xu L-P, Zhang XH, Chen YH, Mo XD, Liu KY, Huang XJ (2018) Utility of flexible bronchoscopy with polymerase chain reaction in the diagnosis and management of pulmonary infiltrates in allogeneic HSCT patients. Clin Transpl 32. https://doi. org/10.1111/ctr.13146

Torda A, Chong Q, Lee A, Chen S, Dodds A, Greenwood M, Larsen S, Gilroy N (2014) Invasive pneumococcal disease following adult allogeneic hematopoietic stem cell transplantation. Transpl Infect Dis 16:751-759. https://doi.org/10.1111/tid.12268

Wieruszewski PM, Herasevich S, Gajic O, Yadav H (2018) Respiratory failure in the hematopoietic stem cell transplant recipient. World $\mathrm{J}$ Crit Care Med 7:62-72. https://doi.org/10.5492/wjccm.v7.i5.62

Yu VL, Chiou CCC, Feldman C, Ortqvist A, Rello J, Morris AJ, Baddour LM, Luna CM, Snydman DR, Ip M, Ko WC, Chedid MBF, Andremont A, Klugman KP, International Pneumococcal Study Group (2003) An international prospective study of pneumococcal bacteremia: correlation with in vitro resistance, antibiotics administered, and clinical outcome. Clin Infect Dis 37:230-237. https://doi. org $/ 10.1086 / 377534$

Zarrinfar H, Makimura K, Satoh K, Khodadadi H, Mirhendi H (2013) Incidence of pulmonary aspergillosis and correlation of conventional diagnostic methods with nested PCR and real-time PCR assay using BAL fluid in intensive care unit patients. J Clin Lab Anal 27:181-185. https://doi.org/10.1002/jcla.21580

Publisher's note Springer Nature remains neutral with regard to jurisdictional claims in published maps and institutional affiliations. 